\title{
An Economic Production Quantity model with inventory dependent demand and deterioration
}

\author{
P.S.Ardak ${ }^{1}$, A.B.Borade ${ }^{2}$ \\ ${ }^{1}$ Department of Mechanical Engineering, P.R.Pote College of Engineering and Management, \\ Amravati, India, 444601. \\ Email:pankajardak@gmail.com \\ ${ }^{2}$ Department of Mechanical Engineering, Jawaharlal Darda Institute of Technology, \\ Yavatmal, India. \\ Email: atulborade@rediffmail.com.
}

\begin{abstract}
EPQ models are used to control the inventory effectively. The present work proposes EPQ model exclusively for deteriorating items. In the present work the EPQ model has been developed by assuming that deterioration of the items start after some constant time as it enters into the inventory. For that during production up time, demand rate is considered as inventory dependent and kept constant during down time. An efficient procedure is developed to find the optimal production run length. The influence of inventory dependent consumption rate on the production up time is also discussed in this model. A numerical example is provided to illustrate the theoretical results. The result of sensitivity analysis indicates that production up time and total cost per unit time, both are highly sensitive to change in production and demand rate. Demand consumption parameter reduces the total inventory and hence holding cost.
\end{abstract}

Keywords:- Deteriorating items, EPQ, Inventory dependent consumption rate, mix demand

\section{INTORDUCTION}

The economic production quantity (EPQ) model has been widely used in practice as it plays an important role on managing the inventory effectively. Classic economic production quantity model assumes that during production run a manufacturing facility functions perfectly and continuous inventory issuing policy for satisfying customer's demand .However, there are some drawbacks in the assumption of the original EPQ model. Many researchers have tried to improve it with different viewpoints. In manufacturing companies, when items are internally produced instead of being obtained from an outside supplier, the Economic Production Quantity (EPQ) model is often employed to determine the optimal production lot size that minimizes overall production/inventory costs. Mishra and Singh developed EPQ model for perishable items by considering demand as a power form function of the inventory level. When deterioration starts, it accelerates with time in case of fast deteriorating items like meat, vegetables milk fruits etc.[1] Behrouz and Babak, developed economic production quantity (EPQ) model by considering both the depreciation cost of stored items and process quality cost. Depreciation cost and process quality cost was assumed to be continuous functions of holding time and of production run length.[2] Yuan et.al derived the optimal manufacturing batch size and number of shipment with scrap using mathematical modeling and algebraic approach[3]. Ata discussed EPQ model for multi products single machine with discrete delivery[4]. Taleizadeh, Naja and Naiki focused on EPQ model with a production capacity limitation and a random defective production rate[5]. Gede and Hui analyzed an EPQ model for deteriorating Items with stochastic machine unavailability and price- dependent demand[6]. Jinn, used time varying demand and cost to analysed EPQ model and characterize the influences of both demand and cost over the length of production run time and the economic production quantity[7] Kuo developed EPQ model by considering setup cost and process quality as a functions of capital expenditure. Disruption in production system is common phenomenon[8]. Khedlekar attempted to established exponential demand in disrupted production system and determine production time before and after disruption[9]. Kapil and Navin developed solution procedure which help, to take decision whether to rent a warehouse or not. Demand considered for this is exponential and time dependent for deteriorating items[10]. Holding cost has been treated as non linear function of time and functional form of on hand inventory by Giri and Chaudhary studied perishable inventory model[11]. Cheng solved EPQ problem by using geometric programming with demand dependent production cost[12],[13]. The imperfect production process has general deterioration distribution and system condition depends upon how long it runs. For such system inspection can check that the process is in control or not[14]. Ram developed lot size model for constant and varying rate of deterioration[15]. Lie introduced EOQ model by assuming that return items from customer were replaced by quality items[16]. Jie et.al. considered inventory dependent demand to developed EPQ model.[17]. 
Most of the inventory models considered various demand patterns like stock dependent demand, power form demand, ramp type of demand, time dependent demand, selling price dependent demand and exponential demand. It is well known that, the demand rate vary with change in inventory level. From the literature review, it is observed that the different demand pattern has not been discussed by any researcher so far on different time period. The present study may be significant in filling this gap since it aims to develop EPQ model by assuming demand as inventory dependent criteria during inventory buildup time and constant during inventory depletion period. This paper has several sections. Research motivation and literature is narrated in introduction. Next section contains notations and assumption. The following sections formulate the model and derives the optimal solutions. The aspect of numerical and sensitivity analysis is discussed in some details followed by some concluding remarks.

\section{ASSUMTIONS AND NOTATIONS}

Following assumption and notations are used to develop the model.

\section{A. Assumptions}

The following assumptions are made in development of the model.

a) The production rate is known and is kept constant.

b) The production rate is greater than the demand.

c) The demand is inventory level dependent in up time and kept constant in down time.

d) Deterioration of the items is at constant rate.

e) Inventory holding cost is known and termed as constant.

f) Deterioration of the items start after some constant time as it enters into inventory.

g) Shortages are not allowed.

h) Every produced items needs inspection

\section{B. Notations}

$I_{1}$ - Inventory level during production up time.

$\mathrm{I}_{2}$ - Inventory level during production down time.

$\mathrm{T}_{1}-$ Production up time up to which no deterioration.

$\mathrm{T}_{2}$ - Production up time in which deterioration start.

$\mathrm{T}_{3}-$ Production down time.

$\mathrm{P}$ - Rate of production.

$\mathrm{D}$ - Basic demand.

$\theta$ - Rate of Deterioration

$\alpha$ - Inventory dependent consumption rate parameter.

$\mathrm{H}$ - Holding cost per unit

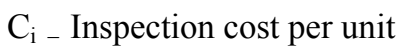

$\mathrm{T}$ - Production cycle time. $\left(\mathrm{T}=\mathrm{T}_{1}+\mathrm{T}_{2}+\mathrm{T}_{3}\right)$

TC - Total cost.

IC - Total Inspection cost.

TCT - Total cost per unit time.

TI - Total Inventory.

\section{MODEL FORMULATION}

Present work deals with an EPQ model for deteriorating items. Inventories are buildup gradually during production up time, new production run will start after complete consumption of the buildup inventory. At the beginning it is assumed that the inventory is zero. As the production rate is greater than the demand rate, inventory is gradually buildup at a rate of (P-D). During production up time the demand rate is inventory dependent. At time $\mathrm{T}_{2}$ the inventory will be maximum. At this stage production is terminated and on hand inventory will be used to meet the demand and to offset the loss due to deterioration. During production down time demand remains constant.

As shown in fig 1,the production will start at $\mathrm{t}=0$, During the time period $\left(0, \mathrm{~T}_{1}\right)$ the inventory will gradually build up with no deterioration. For the time period $\left(0, \mathrm{~T}_{2}\right)$, inventory will build up under the action of inventory dependent demand and deterioration. Maximum inventory will be at time $t=T_{2}$. Later, production stops and buildup inventory is consumed to fulfill the demand. Production system can be described by the following differential equations. 


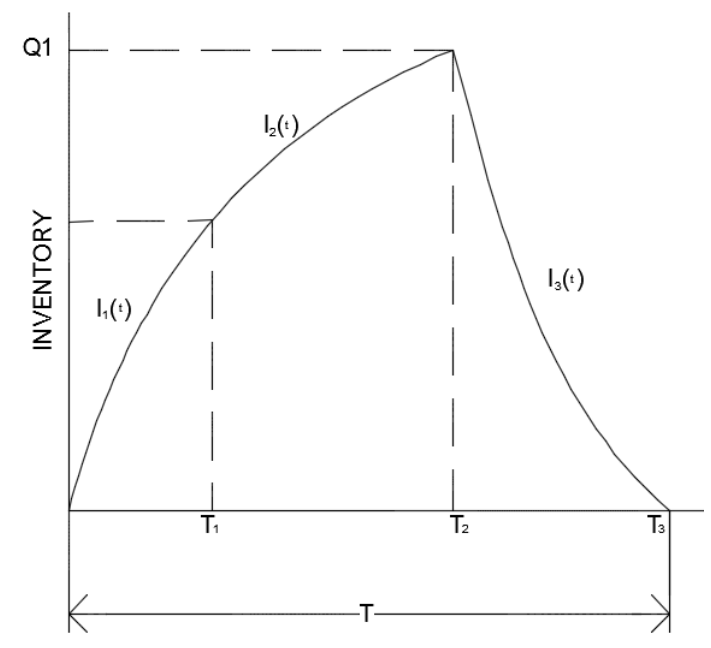

Figure 1. Inventory Level

According to the assumptions, over time span $\left[0, \mathrm{~T}_{1}\right]$, demand rate is inventory dependent and no deterioration, which makes variation of the inventory level with respect to time for the reference time, be governed by.

$$
\frac{\mathrm{dI}_{1}(\mathrm{t})}{\mathrm{dt}}=\mathrm{P}-\mathrm{D}-\alpha \mathrm{I}_{1}(\mathrm{t}) \quad 0 \leq \mathrm{t} \leq \mathrm{T}_{1} \quad 1 .
$$

In the time interval $\left(0, \mathrm{~T}_{2}\right)$, the system is affected by the combined effect of inventory dependent demand and deterioration. Hence, the change in inventory level is governed by the following differential equation.

$$
\frac{d I_{2}(t)}{d t}=P-D-\alpha I_{2}(t)-\theta I_{2}(t) \quad 0 \leq t \leq T_{2} \quad 2 .
$$

In the time interval $\left(0, \mathrm{~T}_{3}\right)$, the system is affected by the combined effect of constant demand and deterioration. Hence, the change in inventory level is governed by the following differential equation.

$$
\frac{\mathrm{dI}_{3}(\mathrm{t})}{\mathrm{dt}}=-\mathrm{D}-\theta \mathrm{I}_{3}(\mathrm{t}) \quad 0 \leq \mathrm{t} \leq \mathrm{T}_{3}
$$

Initial boundary conditions associated with this equations are, at $t=0, I_{1}(t)=0$, at $\quad t=T_{2}, \quad I_{2}\left(T_{2}\right)=Q_{1}$ and at $t=T_{3}, I_{3}\left(T_{3}\right)=0$ the solution to above equations is as follows. These three equations are used in the derivation of our model.

$$
\begin{array}{cc}
I_{1}(t)=\frac{P-D}{\alpha}\left[1-e^{-\alpha t}\right] & 0 \leq t \leq T_{1} \\
I_{2}(t)=\frac{(P-D)}{(\alpha+\theta)}+\left[Q_{1}-\frac{(P-D)}{(\alpha+\theta)}\right] e^{(\alpha+\theta)\left(T_{2}-t\right)} & 0 \leq t \leq T_{2} \\
I_{3}(t)=\frac{D}{\theta}\left[e^{\theta\left(T_{3}-t\right)}-1\right] & 0 \leq t \leq T_{3}
\end{array}
$$

By using initial boundary conditions $\mathrm{I}_{3}(0)=\mathrm{Q}_{1}$

$$
\begin{array}{r}
\frac{\mathrm{D}}{\theta}\left[\mathrm{e}^{\theta\left(\mathrm{T}_{3}\right)}-1\right]=\mathrm{Q}_{1} \\
\mathrm{Q}_{1} \approx \mathrm{DT}_{3}
\end{array}
$$

By using boundary conditions $\mathrm{I}_{2}(0)=0$ and from Eq. 8 


$$
\begin{aligned}
& \frac{(\mathrm{P}-\mathrm{D})}{(\alpha+\theta)}+\left[\mathrm{Q}_{1}-\frac{(\mathrm{P}-\mathrm{D})}{(\alpha+\theta)}\right] \mathrm{e}^{(\alpha+\theta)\left(\mathrm{T}_{2}\right)}=0 \\
& \mathrm{~T}_{3}=\frac{(\mathrm{P}-\mathrm{D})}{\mathrm{D}}\left[\mathrm{T}_{2}-\frac{(\alpha+\theta) \mathrm{T}_{2}^{2}}{2}\right]
\end{aligned}
$$

Total inventory is given by

$$
\mathrm{TI}=\int_{0}^{\mathrm{T}_{1}} \mathrm{I}_{1}(\mathrm{t}) \mathrm{dt}+\int_{0}^{\mathrm{T}_{2}} \mathrm{I}_{2}(\mathrm{t}) \mathrm{dt}+\int_{0}^{\mathrm{T}_{3}} \mathrm{I}_{3}(\mathrm{t}) \mathrm{dt}
$$

Inventory holding cost is given by

$$
\mathrm{HC}=\mathrm{h}\left(\int_{0}^{\mathrm{T}_{1}} \mathrm{I}_{1}(\mathrm{t}) \mathrm{dt}+\int_{0}^{\mathrm{T}_{2}} \mathrm{I}_{2}(\mathrm{t}) \mathrm{dt}+\int_{0}^{\mathrm{T}_{3}} \mathrm{I}_{3}(\mathrm{t}) \mathrm{dt}\right)
$$

All produced items are inspected, inspection cost is given by,

$$
\mathrm{IC}=\mathrm{C}_{\mathrm{i}}\left(\int_{0}^{\mathrm{T}_{1}} \mathrm{I}_{1}(\mathrm{t}) \mathrm{dt}+\int_{0}^{\mathrm{T}_{2}} \mathrm{I}_{2}(\mathrm{t}) \mathrm{dt}\right)
$$

From equations 12 and 13.

Total cost $=$ Set up cost + Holding cost + Inspection cost.

$\mathrm{TC}=\mathrm{A}+\mathrm{HC}+\mathrm{IC}$

$\therefore \mathrm{TC}=\mathrm{A}+\mathrm{h}\left(\int_{0}^{\mathrm{T}_{1}} \mathrm{I}_{1}(\mathrm{t}) \mathrm{dt}+\int_{0}^{\mathrm{T}_{2}} \mathrm{I}_{2}(\mathrm{t}) \mathrm{dt}+\int_{0}^{\mathrm{T}_{3}} \mathrm{I}_{3}(\mathrm{t}) \mathrm{dt}\right)+\mathrm{C}_{\mathrm{i}}\left(\int_{0}^{\mathrm{T}_{1}} \mathrm{I}_{1}(\mathrm{t}) \mathrm{dt}+\int_{0}^{\mathrm{T}_{2}} \mathrm{I}_{2}(\mathrm{t}) \mathrm{dt}\right)$

Production cycle time $=\mathrm{T}=\mathrm{T}_{1}+\mathrm{T}_{2}+\mathrm{T}_{3}$

$\therefore \mathrm{T}=\mathrm{T}_{1}+\mathrm{T}_{2}\left(1+\frac{\mathrm{P}-\mathrm{D}}{\mathrm{D}}\right)+\mathrm{T}_{2}^{2}\left[\frac{(\mathrm{P}-\mathrm{D})}{\mathrm{D}}(\alpha+\theta)\right]$

From equations 14 and 15.

Total cost per unit time

$\mathrm{TCT}=\frac{\mathrm{TC}}{\mathrm{T}}$

$$
\begin{aligned}
\therefore \mathrm{TCT} & =\frac{\mathrm{A}+\mathrm{h}\left(\int_{0}^{\mathrm{T}} \mathrm{I}_{1}(\mathrm{t}) \mathrm{dt}+\int_{0}^{\mathrm{T}_{2}} \mathrm{I}_{2}(\mathrm{t}) \mathrm{dt}+\int_{0}^{\mathrm{T}_{3}} \mathrm{I}_{3}(\mathrm{t}) \mathrm{dt}\right)+\mathrm{C}_{\mathrm{i}}\left(\int_{0}^{\mathrm{T}} \mathrm{I}_{1}(\mathrm{t}) \mathrm{dt}+\int_{0}^{\mathrm{T}_{2}} \mathrm{I}_{2}(\mathrm{t}) \mathrm{dt}\right)}{\mathrm{T}_{1}+\mathrm{T}_{2}\left(1+\frac{\mathrm{P}-\mathrm{D}}{\mathrm{D}}\right)+\mathrm{T}_{2}^{2}\left[\frac{(\mathrm{P}-\mathrm{D})}{\mathrm{D}}(\alpha+\theta)\right]} \\
& =\frac{\mathrm{K}_{1}+\mathrm{T}_{2}^{2} \mathrm{~K}_{2}-\mathrm{T}_{2}^{3} \mathrm{~K}_{3}+\mathrm{T}_{2}^{4} \mathrm{~K}_{4}}{\mathrm{~T}_{1}+\mathrm{T}_{2} \mathrm{~K}_{5}-\mathrm{T}_{2}^{2} \mathrm{~K}_{6}}
\end{aligned}
$$


Where,

$$
\begin{aligned}
& \mathrm{K}_{1}=\mathrm{A}+\left(\mathrm{h}+\mathrm{C}_{\mathrm{i}}\right) \frac{(\mathrm{P}-\mathrm{D})}{2} \mathrm{~T}_{1}^{2} \\
& \mathrm{~K}_{2}=\left(\mathrm{h}+\mathrm{C}_{\mathrm{i}}\right) \frac{\mathrm{P}-\mathrm{D}}{2}+\frac{\mathrm{h}}{2 \mathrm{D}}(\mathrm{P}-\mathrm{D})^{2} \\
& \mathrm{~K}_{3}=\frac{\mathrm{h}}{2 \mathrm{D}}(\mathrm{P}-\mathrm{D})^{2}(\alpha+\theta) \\
& \mathrm{K}_{4}=\frac{\mathrm{h}}{8 \mathrm{D}}(\mathrm{P}-\mathrm{D})^{2}(\alpha+\theta)^{2} \\
& \mathrm{~K}_{5}=\left(1+\frac{\mathrm{P}-\mathrm{D}}{\mathrm{D}}\right) \\
& \mathrm{K}_{6}=\frac{\mathrm{P}-\mathrm{D}}{2 \mathrm{D}}(\alpha+\theta)
\end{aligned}
$$

The optimum production up time can be derived by satisfying the equation 17 .

$$
\frac{\mathrm{dTCT}}{\mathrm{dT}_{2}}=0
$$

Ignoring the higher power terms of $\mathrm{T}_{2}$, following quadratic equation_can be obtained.

$$
\mathrm{T}_{2}^{2}\left[\mathrm{~K}_{2} \mathrm{~K}_{5}-3 \mathrm{~T}_{1} \mathrm{~K}_{3}\right]+\mathrm{T}_{2}\left[2 \mathrm{~T}_{1} \mathrm{~K}_{2}-2 \mathrm{~K}_{1} \mathrm{~K}_{6}\right]-\mathrm{K}_{1} \mathrm{~K}_{5}=0
$$

The closed form solution can be obtained by considering positive root of the equation.

\section{NUMERICAL AND SENSITIVITY ANALYSIS}

Numerical example and sensitivity analysis has been carried out to validate the theoretical aspects. The numerical data is adopted from (Jie,)[17] except some additional data like set up cost and inspection cost. $\mathrm{A}=$ Rs. 30 per production cycle, $\mathrm{C}_{\mathrm{i}}=$ Rs 2 per unit per unit time, $\mathrm{h}=$ Rs. 2 per unit per unit time, $\mathrm{P}=2500$ units per unit time, $\mathrm{D}=1200$ units per unit time, $\alpha=0.5, \theta=0.1$

The optimum value of $T_{2}$ can be found, as the total cost function is convex (Fig. 2). The optimum value of $T_{2}$ is 0.221 The optimum total cost per unit time is TCT $=$ Rs.763.26. Sensitivity analysis is carried out by changing each parameter by $-40 \%$ to $+40 \%$, taking one parameter at a time and keeping others unchanged.

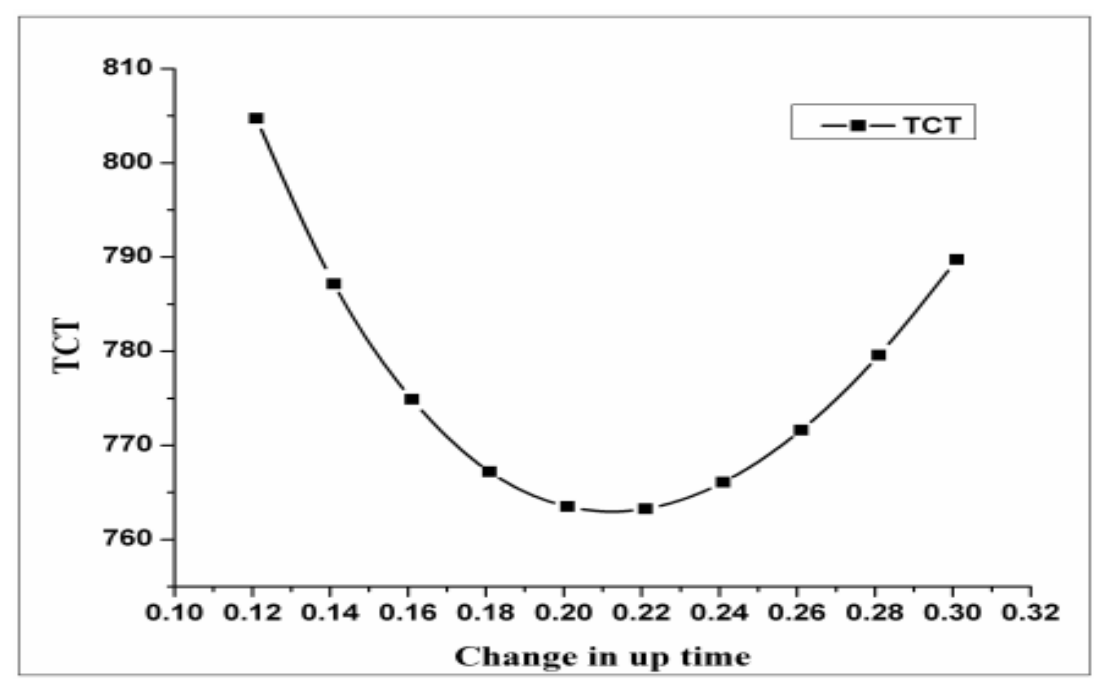

Figure 2.TCT v/s up time 
Table 1. Sensitivity analysis of $\mathrm{T}_{2}$

\begin{tabular}{|c|c|c|c|c|c|c|c|c|}
\hline \multicolumn{10}{|c|}{ Parameter changes } \\
\hline \multirow{3}{*}{ Parameters } & \multicolumn{2}{|c|}{$\mathbf{4 0 \%}$} & \multicolumn{2}{|c|}{$\mathbf{- 2 0} \%$} & \multicolumn{2}{|c|}{$\mathbf{2 0 \%}$} & \multicolumn{2}{|c|}{$\mathbf{4 0 \%}$} \\
\cline { 2 - 10 } & $\mathbf{T}_{\mathbf{2}}$ & $\mathbf{T C T}$ & $\mathbf{T}_{\mathbf{2}}$ & $\mathbf{T C T}$ & $\mathbf{T}_{\mathbf{2}}$ & $\mathbf{T C T}$ & $\mathbf{T}_{\mathbf{2}}$ & $\mathbf{T C T}$ \\
\hline $\mathrm{P}$ & 0.254 & 228.63 & 0.229 & 511.8 & 0.214 & 991.27 & 0.208 & 1203.19 \\
\hline $\mathrm{D}$ & 0.203 & 886.55 & 0.214 & 843.00 & 0.225 & 659.80 & 0.228 & 538.66 \\
\hline$\alpha$ & 0.222 & 759.02 & 0.221 & 761.09 & 0.220 & 765.32 & 0.220 & 767.45 \\
\hline $\mathrm{h}$ & 0.237 & 569.49 & 0.227 & 666.55 & 0.216 & 859.66 & 0.212 & 955.86 \\
\hline$\theta$ & 0.221 & 762.39 & 0.221 & 762.82 & 0.221 & 763.65 & 0.221 & 764.09 \\
\hline $\mathrm{Ci}$ & 0.212 & 663.63 & 0.217 & 713.54 & 0.224 & 812.81 & 0.228 & 862.33 \\
\hline
\end{tabular}

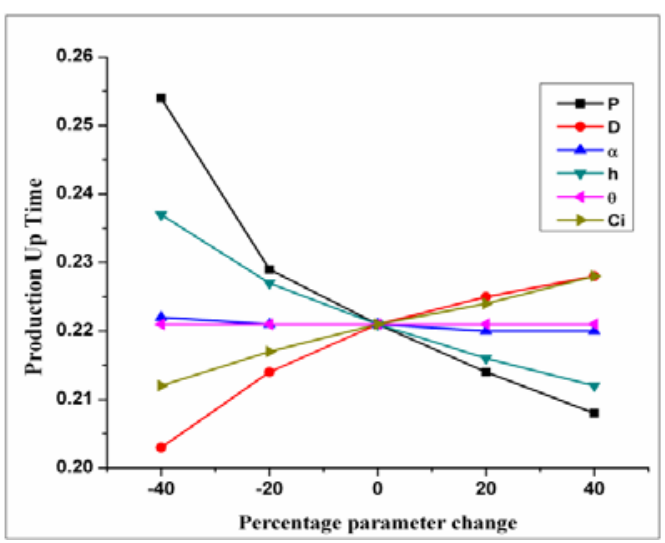

Figure 3. $\mathrm{T}_{2} \mathrm{~V} / \mathrm{S}$ Parameter Change

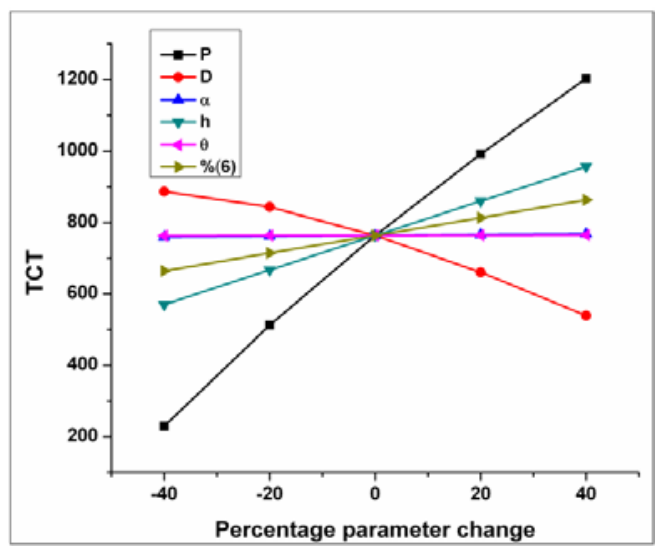

Figure 4. TCT V/S Parameter Change

As shown in Fig.3, Production uptime is highly sensitive to production rate, demand rate. It is moderately sensitive to holding cost and inspection cost while it is slightly sensitive to deterioration rate and inventory consumption rate. Production up time decreases due to increase in the production rate. For the first $40 \%$ increase in the production rate, it is observed that rate of decrease in the production up time is more as compared to last $40 \%$ increase in production rate. When rate of production is higher, inventory will build at higher rate. As the demand is inventory dependent in the production up time, net demand of the product increases. This indicates that at higher rate of production demand is higher so inventory will build up at slower rate. Production up time increases due to increase in the demand rate.

From fig.4, It is observed that total cost per unit time is highly sensitive to production and demand rate. It is moderately sensitive to holding and inspection cost while slightly sensitive to inventory consumption parameter and deterioration rate.

Table 2. Sensitivity analysis of $T_{3}$

\begin{tabular}{|c|c|c|c|c|}
\hline \multicolumn{5}{|c|}{ Parameter changes } \\
\hline \multirow{2}{*}{ Parameters } & $\mathbf{- 4 0 \%}$ & $\mathbf{- 2 0 \%}$ & $\mathbf{2 0 \%}$ & $\mathbf{4 0 \%}$ \\
\cline { 2 - 5 } & $\mathbf{T}_{\mathbf{3}}$ & $\mathbf{T}_{\mathbf{3}}$ & $\mathbf{T}_{\mathbf{3}}$ & $\mathbf{T}_{\mathbf{3}}$ \\
\hline $\mathrm{P}$ & 0.058 & 0.142 & 0.300 & 0.373 \\
\hline $\mathrm{D}$ & 0.471 & 0.321 & 0.158 & 0.103 \\
\hline$\alpha$ & 0.229 & 0.225 & 0.219 & 0.216 \\
\hline $\mathrm{H}$ & 0.237 & 0.228 & 0.218 & 0.214 \\
\hline$\Theta$ & 0.223 & 0.223 & 0.223 & 0.223 \\
\hline $\mathrm{Ci}$ & 0.214 & 0.219 & 0.225 & 0.229 \\
\hline
\end{tabular}




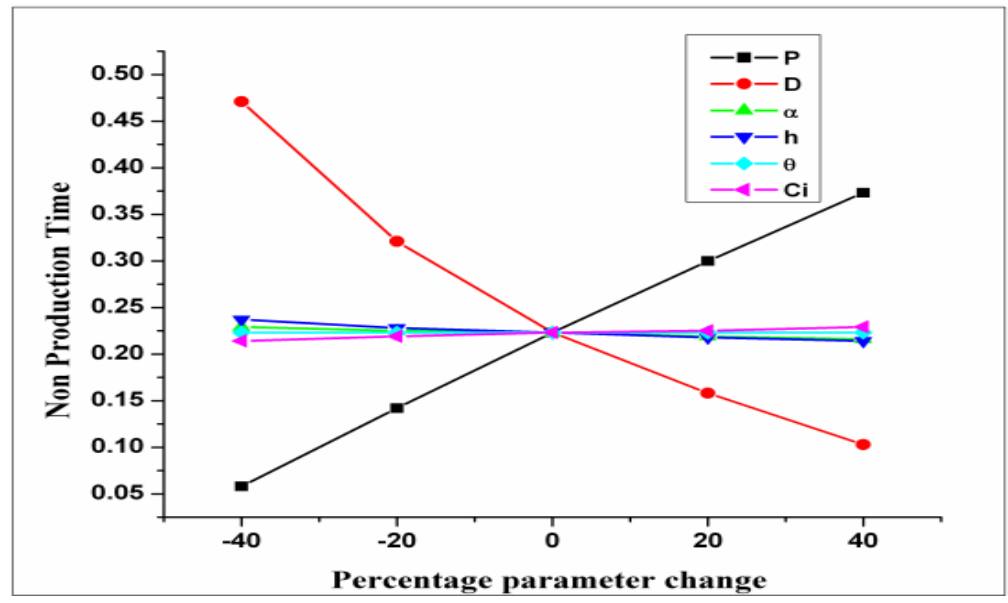

Figure 5. $T_{3} V / S$ Parameter change

Fig. 5 shows that non production time is highly sensitive to production and demand rate. It is slightly sensitive to holding cost, inspection cost, inventory consumption parameter and deterioration rate.

Table 3. Values of HC and TI for different values of $\alpha$

\begin{tabular}{|c|c|c|}
\hline $\mathbf{A}$ & HC & TI \\
\hline 0.3 & 451.98 & 225.99 \\
\hline 0.4 & 449.24 & 224.62 \\
\hline 0.5 & 448.16 & 224.08 \\
\hline 0.6 & 445.46 & 222.72 \\
\hline 0.7 & 443.9 & 221.95 \\
\hline
\end{tabular}

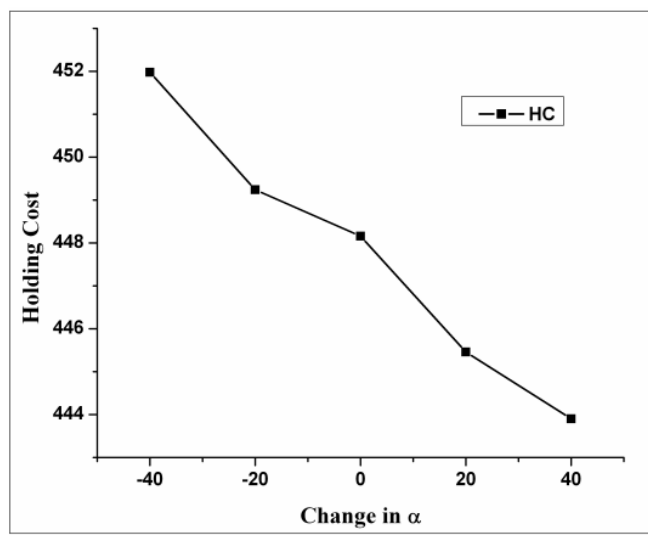

Fig.6: Demand parameters $\alpha$ v/s Holding Cost

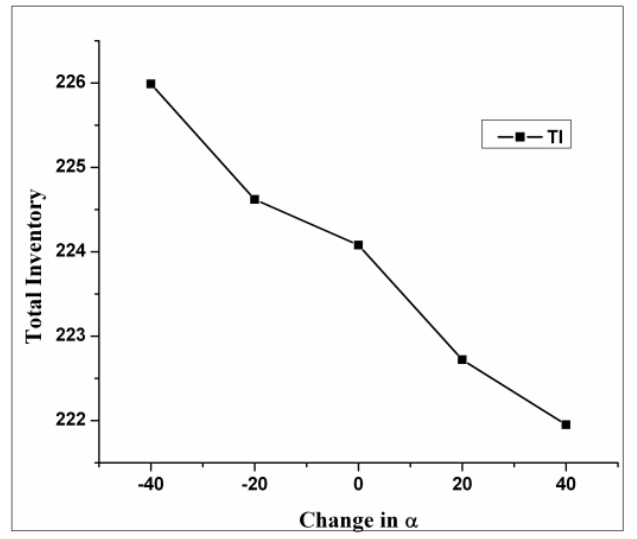

Fig.7:Demand parameters $\alpha \mathrm{v} / \mathrm{s}$ Total inventory

Fig. 6 and 7 shows that holding cost and total inventory is sensitive to change in parameter $\alpha$. It is observed from Fig 3 that, TCT increases with increase in the production rate. This happens because increase in production rate increases the inventory and hence the holding cost. But if the demand pattern is inventory level dependent, then increase in inventory increases the demand and hence decrease in total inventory and decrease in inventory holding cost. Subsequently it can be commented referring Fig. 6 that, increase in the inventory dependent consumption rate parameter decreases the holding cost. Again from Fig.7 increase in $\alpha$ decrease the total inventory. This attracts the attention of inventory managers to estimate the accurate value of the inventory dependent consumption rate parameter. 


\section{CONCLUSION}

In this study, theoretical EPQ model has been developed over an infinite horizon. During inventory buildup time, demand used is inventory level dependent, and during inventory depletion it is constant. No deterioration for time period $\left(0, \mathrm{~T}_{1}\right)$ and there after constant deterioration rate. Increase in demand parameter $\alpha$ decreases the holding cost and total inventory. Sensitivity analysis shows that TCT as well as production up and down time are highly sensitive to production and demand rate. Increase in inventory dependent consumption parameter decrease the total inventory and hence holding cost. This indicates that higher inventory stock can attract the customer to buy more. This model can be useful for the inventory managers in decision making especially for the perishable items. The model can be further developed by considering different deterioration rate, production rate.

\section{REFERENCES}

[1] Mishra, S. S., Singh, P. K. A Computational Approach to EOQ Model with Power-Form Stock-Dependent Demand and Cubic Deterioration. American Journal of Operational Research,1(1), 5-13,2011.

[2] Behrouz ,A. N., Babak, A. EPQ model with depreciation cost and process quality cost as continuous functions of time. International Journal of Industrial Engineering 5, (8), 77-89,2009.

[3] Yuan,S. C., Hong,D. L., Ming,H. H., Nong, P., “ Computational Optimization of Manufacturing Batch Size and Shipment for an Integrated EPQ Model with Scrap". American Journal of Computational Mathematics, 1, 202-207,2011.

[4] Ata ,A. T., Gede ,A. W., Hui, M. W. , Jahangir ,B. "Multi products single machine economic production quantity model with multiple batch size". International Journal of Industrial Engineering Computations, 2, 213-224,2011.

[5] Taleizadeh,A., Naja,A.A., Niaki,S.T.A. ,Economic Production Quantity Model with Scrapped Items and Limited Production Capacity, Transaction E: Industrial Engineering, 17 (1)), 58-69.

[6] Gede, A. W., Hui, M. W. "Production Inventory Models for Deteriorating Items with Stochastic Machine Unavailability Time, Lost Sales and Price Dependent Demand.” Jurnal Teknik Industri, 12, (2), 61-68,2010.

[7] Jinn,T. T., Liang,Y. O., Chun,T. C. "Deterministic economic production quantity models With time-varying demand and cost."Applied Mathematical Modelling ,29, 987-1003,2007.

[8] Kuo,L.H.,."An EPQ model with set up cost and process quality as function of capital expenditure". Applied Mathematical Modelling,31,10 -17,2007.

[9] Khedlekar,U.K. "A disruption production model with exponential demand". International Journal of Industrial Engineering Computations ,3, 607-616,2012.

[10] Kapil, K. B., Navin, A. "Integrated Inventory Models for Decaying Items with Exponential Demand under Inflation". International Journal of Soft Computing and Engineering, 2, (3),578-587,2012.

[11] Girl,B.S., Chaudhuri,K.S. "Deterministic models of perishable inventorywith stock-dependent demand rate and nonlinear holding cost". European Journal of Operational Research, 105, 467-474,1998.

[12] Cheng,T.C.E, "Economic production quantity for profit maximization", International Journal of Systems Science,21,(9), 1889-1894, 1990.

[13] Cheng, T.C.E. “An Economic Order Quantity Model with Demand Dependent Unit Production Cost and Imperfect Production Processes" lIE Transactions, 23,( I),1991.

[14] Singa,W.C., Yuan,S.P.C. "Mathematical modeling for production system with backlogging and repairs in failure."Journal of scientific and Industrial research,65,499-506,2006.

[15] Ram , B. M. "Optimum production lot size model for a system with deteriorating inventory". International Journal of Production Research, 13,(5), 495-505,1975.

[16] Lie,F.H. "A note on An economic order quantity (EOQ) for items with imperfect quality and inspection errors". International Journal of Industrial Engineering Computations ,3,2012.

[17] Jie, M., Yong, W.Z., Gui, Q.L., Sheng, D.W. "An EPQ model for deteriorating items with inventory level dependent demand and permissible delay in payments". International Journal of Systems Science, 43(6), 1039-1053,2012. 